\title{
AS RESENHAS DA \\ CARTA SOBRE A TOLERÂNCIA DE JOHN LOCKE: CONTEXTUALIZAÇÃO E TRADUÇÃO
}

\section{Flavio Fontenelle Loque ${ }^{1}$}

\begin{abstract}
RESUMO
A recepção da Carta sobre a Tolerância de John Locke se deu em três vertentes distintas: traduções, resenhas e críticas. O objetivo do presente artigo consiste em tratar de uma dessas vertentes, as resenhas, com o intuito de (i) contextualizá-las brevemente levando em conta tanto a dinâmica da República das Letras quanto os princípios editoriais dos periódicos eruditos em que foram publicadas e (ii) traduzi-las para o português acrescentando-lhes alguns esclarecimentos em notas de rodapé.
\end{abstract}

Palavras-Chave: Carta sobre a Tolerância. Recepção. Resenha. Le Clerc. Basnage de Beauval. Tradução.

\begin{abstract}
The reception of John Locke's Epistola de Tolerantia consisted in three different approaches: translations, reviews and critiques. This article focuses on one of them, the reviews, in order (i) to make a brief exposition of the their context taking into account the dynamics of the Republic of Letters as well as the editorial principles of the learned journals that published them, and (ii) to translate them into Portuguese adding some clarifications in footnotes.
\end{abstract}

Keywords: Epistola de Tolerantia. Reception. Reviews. Le Clerc. Basnage de Beauval. Translation.

\section{Introdução}

A publicação da Carta sobre a Tolerância de John Locke (16321704) ocorreu em abril de 1689, mesmo ano do Ensaio sobre o Entendimento Humano e dos Dois Tratados sobre o Governo. Todavia, ao contrário dessas duas obras, cujos originais estão em inglês e cuja publicação se deu em Londres, a Carta sobre a Tolerância foi impressa em Gouda, na Holanda, e

\footnotetext{
${ }^{1}$ Doutor em filosofia pela Universidade Federal de Minas Gerais (UFMG). Professor adjunto da Universidade Federal de Itajubá - campus de Itabira (UNIFEI).

Email: flavioloque@yahoo.com. ORCID: 0000-0002-6921-8695.
} 
em latim. Locke a havia composto no inverno europeu de 1685-1686 e, ao retornar para seu país em fevereiro de 1689 depois de cinco anos e meio de exílio, deixou o manuscrito com o teólogo e amigo Philip van Limborch (1633-1712), que ficou responsável pela supervisão da publicação. Em setembro de 1689, Limborch reportou a Locke que uma tradução holandesa estava à venda e que era lida com aprovação. Em outubro, uma nova tradução, agora para o inglês, foi publicada em Londres (uma segunda edição, corrigida, apareceria em março de 1690). Em julho, Limborch havia projetado que uma tradução francesa também sairia naquele ano, aparentemente antes dessas outras duas, o que acabou não acontecendo. ${ }^{2} \mathrm{~A}$ obra só pôde ser lida em francês em 1710, numa coletânea publicada em Roterdã com o título Euvres Diverses de Monsieur Jean Locke.

Além das traduções, a recepção imediata da Carta sobre a Tolerância envolveu outros dois tipos de abordagem: por um lado, as resenhas na Bibliothèque Universelle et Historique (25 vol., Amsterdã, 1686-1693) e nas Histoires des Ouvrages des Sçavans (24 vol., Roterdã, 1687-1709), dois dos principais periódicos eruditos da época; por outro, as críticas feitas pelos clérigos anglicanos Thomas Long (1621-1707) e Jonas Proast (c. 16421710) que publicaram, respectivamente, $A$ 'Carta sobre a Tolerância' decifrada e o absurdo e impiedade de uma tolerância absoluta demonstrados (Londres, 1689) e O Argumento da 'Carta sobre a Tolerância' brevemente analisado e respondido (Oxford, 1690). ${ }^{3}$

Dessa recepção multiface da Carta sobre a Tolerância, todavia, interessa ao presente artigo tratar apenas das resenhas. O objetivo aqui é (i) contextualizá-las brevemente levando em conta tanto a dinâmica da República das Letras quanto os princípios editoriais dos periódicos em que foram publicadas e (ii) traduzi-las para o português acrescentando-lhes alguns esclarecimentos em notas de rodapé.

\footnotetext{
${ }^{2}$ As informações sobre a supervisão da publicação da Carta sobre a Tolerância e sua tradução para o holandês e francês encontram-se na correspondência entre Limborch e Locke, cf. Locke (1976-89, v. III, cartas 1158, 1178; v. IV, carta 1283).

${ }^{3}$ Outras duas publicações também integram a recepção imediata da Carta sobre a Tolerância: o Tableau du Socinianisme (1690) de Pierre Jurieu (1637-1713) e a Lettre écrite de Suisse en Hollande (1690) de Gédéon Huet (†1728). Nenhuma delas, porém, explora a Carta sobre a Tolerância em detalhe. Jurieu a critica, mas, dadas as referências que apresenta (cf. p. 212, 436, 508, 511, 528), parece ter lido apenas a resenha publicada nas Histoires des Ouvrages des Sçavans. Já Huet se limita a um elogio genérico feito num curto post scriptum.
} 


\section{Contextualização}

Na segunda metade do século XVII, a Holanda se tornou o refúgio de inúmeras pessoas perseguidas por razões religiosas e políticas. O objetivo maior dos exilados, evidentemente, era proteger as próprias vidas, mas, quanto aos filósofos e teólogos, eles também buscavam um ambiente em que pudessem publicar suas obras com maior facilidade. Uma das consequências desse afluxo para a Holanda foi o estabelecimento de uma rede de colaboração entre defensores da tolerância que envolvia auxílio material (ajuda financeira, compra e transporte de livros, indicações para postos de trabalho) e cooperação intelectual (encontros de discussão e apoio para publicação), mas cujo grande objetivo era a promoção do próprio conceito de tolerância, o que se fazia por meio de traduções, resenhas, citações e recomendações de leitura (cf. Marshall, 2006, p. 469-535). Em grande medida, essa rede de colaboração - da qual faziam parte Locke e Limborch, mas ainda Jean Le Clerc (1657-1736), Henri Basnage de Beauval (1656-1710) e Pierre Bayle (1647-1706), para citar apenas alguns - congregava os membros da chamada República das Letras e utilizava os periódicos eruditos como veículo para dar a conhecer as obras tolerantistas, incentivando assim que fossem não apenas lidas, mas ainda traduzidas para outras línguas. ${ }^{4} \mathrm{~A}$ esse respeito, três periódicos são emblemáticos: as Nouvelles de la République des Lettres, a Bibliothèque Universelle et Historique e as Histoires des Ouvrages des Sçavans, respectivamente editados (ao menos a princípio) por Bayle, Le Clerc e Basnage de Beauval (cf. Bots, 1977). ${ }^{5}$

Sendo assim, considerando-se a existência desse fórum intelectual e do propósito de promover a tolerância, convém observar que o fato de ter sido objeto de duas resenhas não faz da Carta sobre a Tolerância um caso excepcional. As recensões eram parte constitutiva da dinâmica da República das Letras em prol da divulgação de obras tolerantistas, o que significa que

\footnotetext{
${ }^{4}$ Desde a segunda metade do século XVII, vale lembrar, o francês estava assumindo o posto de língua franca, o que tornava as resenhas (e, idealmente, as traduções) ainda mais importantes para que as obras em latim fossem conhecidas, caso da Carta sobre a Tolerância. Acerca do domínio do francês, do latim e também do inglês no final do século XVII, cf. Soulard (2012, p. 107-111).

5 A redação da Bibliothèque Universelle et Historique, no entanto, era inicialmente partilhada entre Le Clerc e Jean Cornand de La Crose (1661-1705), cf. Bots (1977, p. 51) e Bots (1991).
} 
outros títulos com a mesma temática tiveram uma recepção análoga. Vejase, por exemplo, os seguintes casos: (i) Tolérance des Réligions (1684), de Basnage de Beauval, anunciada com um comentário no volume correspondente a junho de 1684 das Nouvelles de la République des Lettres; (ii) De nuperis Anglice motibus Epistola (1685), de Adrian Paets (c. 1630-1685), resenhada no volume de outubro de 1685 também das Nouvelles de la République des Lettres e traduzida para o francês pelo próprio Bayle, que ainda providenciou que fosse publicada em holandês; (iii) A Relation of the death of the primitive persecutors (1687), obra atribuída a Lactâncio traduzida $\mathrm{e}$ prefaciada por Gilbert Burnet (1643-1715), que ganhou uma versão para o francês por Jacques Basnage (1653-1723), irmão de Basnage de Beauval, e que foi resenhada no volume correspondente a setembro de 1687 tanto das Nouvelles de la République des Lettres quanto das Histoires des Ouvrages des Sçavans (tomo I); (iv) a Lettre écrite de Suisse en Hollande (1690), de Gédéon Huet (†1728), resenhada na seção de fevereiro de 1690 das Histoires des Ouvrages des Sçavans no volume referente a dezembro de 1689, janeiro e fevereiro de 1690 (tomo VI) e anunciada com uma nota na seção de março desse mesmo ano da Bibliothèque Universelle et Historique no volume referente a janeiro, fevereiro e março de 1690 (tomo XVI). Exemplos suplementares poderiam ser aqui listados, mas esses quatro bastam para mostrar que a Carta sobre a Tolerância recebeu um tratamento semelhante ao de outras obras que tratam da mesma matéria.

Além da dinâmica da República das Letras, há um segundo elemento a destacar acerca das resenhas que a Carta sobre a Tolerância recebeu, o qual diz respeito aos princípios editoriais expressos no prefácio dos tomos inaugurais dos periódicos em que elas foram publicadas: Bibliothèque Universelle et Historique e Histoires des Ouvrages des Sçavans. Basicamente, os editores defendiam que as resenhas fossem descritivas, correspondendo assim a um padrão que eles próprios expressaram nos seguintes termos: "simplesmente não se fará nada senão narrar a opinião dos autores" (Le Clerc, 1688, pref.) e, "com relação à maneira com que falaremos dos livros, nós nos ateremos inquebrantavelmente à mediania entre a servidão dos bajuladores e a severidade dos censores" (Basnage de Beauval, 1687, pref.). É bem verdade que em alguns casos esse padrão não foi seguido à risca, como 
aconteceu na resenha da Segunda Carta sobre a Tolerância de Locke, feita em conjunto com O Argumento da 'Carta sobre a Tolerância' brevemente analisado e respondido de Proast, publicada na seção de outubro do volume referente a outubro, novembro e dezembro de 1690 da Bibliothèque Universelle et Historique (tomo XIX). ${ }^{6}$ Os excessos na elaboração das resenhas eram, contudo, algo a evitar, como se lê em carta a Bayle de 3 de junho de 1684 na qual, referindo-se aos primeiros tomos das Nouvelles de la République des Lettres, Le Clerc lhe aponta que "o que se deseja não é ter todos os meses reflexões do autor sobre os livros que são impressos, mas resenhas fiéis por meio das quais se possa ver se eles merecem ser comprados ou lidos" (Le Clerc, 1987-1997, v. 1, 49, p. 177). As duas resenhas da Carta sobre a Tolerância apresentam sem dúvida alguns juízos valorativos, mas isso não compromete a intenção de reportar o conteúdo da obra. Ambas são de natureza eminentemente descritiva, em especial aquela publicada na $B i$ bliothèque Universelle et Historique, cujas seções, numeradas com algarismos romanos, buscam reproduzir a estrutura da obra e abarcá-la completamente.

A recepção da Carta sobre a Tolerância, por conseguinte, ao menos no que diz respeito às resenhas, enquadra-se tanto na dinâmica típica da República das Letras (que fazia das recensões um meio de divulgação de obras tolerantistas) quanto nos princípios editoriais dos periódicos que as publicaram (que estabeleciam a descrição como o padrão a ser seguido).

\section{Tradução}

A resenha da Carta sobre a Tolerância publicada na Bibliothèque Universelle et Historique constitui o artigo XIV na seção de dezembro do

\footnotetext{
${ }^{6}$ Note-se, a título de completude, que a Terceira Carta sobre a Tolerância de Locke também foi resenhada, mas nas Histoires des Ouvrages des Sçavans no volume referente a setembro, outubro e novembro de 1693.

${ }^{7}$ Dessa perspectiva, não parece precisa a observação de Soulard (2019, p. 209) segundo a qual as resenhas são "muito diferentes". Acerca dos juízos valorativos, o prefácio das Histoires des Ouvrages des Sçavans posiciona-se da seguinte maneira: "buscaremos dar aos bons autores uma parte da justiça que lhes é devida e fazer com que os medíocres sintam o que deles pensamos, mas com muita sobriedade com relação a uns e outros para não ferir ninguém com uma discrepância demasiado notória". Tratando especificamente da Bibliothèque Universelle et Historique, Milton (2011, p. 442) afirma que os artigos de cada volume, em sua maior parte, eram resenhas "na forma de sumário mais do que de avaliações críticas".
} 
volume referente aos meses de outubro, novembro e dezembro de 1689 (tomo XV), originalmente publicado em 1690. Já a resenha que saiu nas Histoires des Ouvrages des Sçavans consiste no artigo II da seção de setembro do volume que abarca os meses de setembro, outubro e novembro de 1689 (tomo VI) e que foi publicado ainda em $1689 .{ }^{8}$ Ambas foram escritas em francês e nenhuma traz a indicação da autoria. Supõe-se, no entanto, que seus autores sejam os editores de cada um dos periódicos: Jean Le Clerc e Henri Basnage de Beauval.

A referência bibliográfica que encabeça as resenhas incorpora ao título os criptogramas que contêm a dedicatória da obra. Segundo a explicação de Le Clerc no Elogio histórico do finado Sr. Locke, "ao ilustre senhor T.A.R.P.T.O.L.A. escrita por P.A.P.O.I.L.A.” significa “ao ilustre senhor professor de teologia dos remonstrantes, que odeia a tirania, da família Limborch de Amsterdã escrita por um amigo da paz que odeia a perseguição, John Locke, inglês" (cf. Le Clerc, 1732, p. lii). ${ }^{9}$ A indicação in- $12^{\circ}$ descreve o formato do livro.

\subsection{Bibliothèque Universelle et Historique}

XIV

Epistola DE TOLERANTIA ad Clarissimum Virum T.A.R.P.T.O.L.A. Scripta à P.A.P.O.I.L.A. Goudæ apud J. ab Hoeve 1689 in- $12^{\circ}$ pag. $96 .{ }^{10}$

Havíamos decido colocar essa pequena obra no tomo precedente, ${ }^{11}$ mas, tendo-a esquecido, não sei como, nós a colocamos aqui. As pequenas peças não merecem menos do que as grandes que as façamos conhecidas do

\footnotetext{
${ }^{8}$ Os detalhes acerca das edições e tomos desses periódicos são labirínticos. Uma boa fonte de informações é o Le Gazetier Universel: http://gazetier-universel.gazettes18e.fr/ A esse

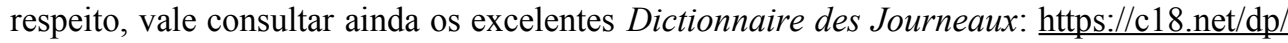
e Dictionnaire des Journalistes http://dictionnaire-journalistes.gazettes18e.fr/

${ }^{9}$ Em carta a Lady Masham de 24 de março de 1705, entretanto, Limborch apresenta outro sentido para as siglas L.A. do primeiro criptograma, que, segundo ele, devem ser lidas como "amante da liberdade" e não "da família Limborch de Amsterdã" (cf. Simonutti, 1999, p. 322).

${ }^{10}$ Texto-base da tradução: Bibliothèque Universelle et Historique de l'année M.D.C.LXXXIX, tome quinzième. Seconde édition révûe et corrigée Amsterdam: chez les héritiers d'Antoine Shelte, MDC XCIX. p. 402-412.

${ }^{11}$ Ou seja, no volume referente aos meses de julho, agosto e setembro de 1689 (tomo XIV).
} 
público, quando abordam matérias importantes, tal qual esta de que trata este livro, cujo resumo se encontra a seguir.

I. O autor começa mostrando que a tolerância é a verdadeira marca da Igreja Cristã, sendo todas as outras de que se fala equívocas em si mesmas e incapazes de formar a essência da verdadeira igreja de Jesus Cristo sem a caridade, como o Evangelho ensina. Ora, sem a tolerância, não há caridade, pois não se pode dizer que desonrar as pessoas, impedi-las de ganhar a vida, expulsá-las, retirar-lhes os bens, fazê-las morrer, como fazem os que não têm tolerância contra aqueles que não partilham suas crenças, sejam ações compatíveis com a caridade. Se fosse o desejo de salvar as almas que animasse os fanáticos, ${ }^{12}$ eles não fariam os heréticos empedernidos morrer, pois isso, segundo eles, consiste certamente em condená-los à danação; e, ademais, eles seriam tão severos contra os vícios que condenam à danação, segundo o Evangelho, se neles nós perseveramos, quanto contra aquilo que acreditam ser erros.

II. Com receio ${ }^{13}$ de que se creia que o bem do Estado requer que se persiga ou que a piedade dos magistrados os obriga a isso, o autor quer que se distinga com cuidado a República da Igreja. A República é uma sociedade estabelecida para a conservação e para o aumento dos bens, que o autor chama de civis, isto é, a vida, a liberdade, a tranquilidade, as posses, etc. Ele sustenta que o magistrado foi encarregado apenas do cuidado dessas coisas exteriores e que seu poder de modo algum diz respeito à salvação das almas. Isso ele prova com estas três razões. Em primeiro lugar, o cuidado com a salvação dos outros não foi confiado ao magistrado mais do que aos outros cidadãos nem pelo céu, nem pelos homens. Deus não disse em parte alguma que entendia que os povos devessem ser da religião de seus príncipes; e ninguém pode razoável nem sinceramente se obrigar a crer no que seu príncipe quiser. Em segundo lugar, o magistrado não tem nada a mais do que os outros homens senão a força, que não pode ser de utilidade alguma nesse ponto, porque a força não persuade e, sem a persuasão interior, não há religião. Em terceiro lugar, supondo-se que a força pudesse persuadir, seria impossí-

\footnotetext{
${ }^{12}$ Le Clerc usa zelateurs. Em contexto análogo, Basnage de Beauval emprega zélez. Ambos os termos correspondem a zelotae no original latino da Carta sobre a Tolerância (cf. Locke, 2019, p. 34-35) e remetem à noção de zelo (zelum).

${ }^{13}$ Pag. 10. (Nota de Le Clerc.) Cf. Locke, 2019, p. 39.
} 
vel ser salvo a menos que se vivesse sob um príncipe ortodoxo, isto é, haveria apenas um número muito pequeno de pessoas que poderia ser salvo por ter a sorte de ter nascido sob um príncipe ortodoxo e de permanecer em seus Estados.

III. A Igreja ${ }^{14}$ é, segundo o autor, uma sociedade de pessoas que se reúnem conjuntamente por sua vontade para servir a Deus publicamente, como crêem que é preciso fazer para ser salvo. Ninguém nasce membro de uma Igreja porque seu pai o é; ninguém é obrigado a seguir uma certa religião simplesmente porque a encontrou estabelecida no local em que nasceu. Como se trata aqui apenas da salvação e de modo algum dos bens terrenos, a coerção não pode ter lugar.

IV. ${ }^{15}$ Sendo assim, é preciso saber quais devem ser os deveres de cada um com relação à tolerância. Em primeiro lugar, caso se considere o corpo da Igreja, ela não é obrigada a reconhecer como membros da sociedade aqueles que não querem observar suas leis. Contudo, é preciso tomar cuidado para que essa exclusão se faça sem nenhuma violência pela qual os excomungados possam se queixar de que seus bens civis sofreram subtração, bens sobre os quais a Igreja não tem direito algum. Como, de sua parte, eles não têm nenhum direito civil nessa sociedade e em suas cerimônias, eles também não podem empregar a força para dela participar, nem se queixar de que se lhes faz algum mal quando não lhes é dada uma parte no pão e no vinho que não foram comprados com seu dinheiro. Em segundo lugar, nenhum indivíduo tem o direito de se apossar dos bens civis de uma pessoa porque ela não é de sua religião. Há uma obrigação de observar para com todos os homens, seja de que crença forem, todos os deveres da sociedade civil que, de sua parte, eles observam. Ocorre o mesmo com as Igrejas particulares umas com relação às outras. Elas não têm nenhum direito civil em virtude do qual possam se molestar reciprocamente; e, com relação a suas leis particulares, dado que cada uma tem o direito de estabelecê-las como lhe aprouver, não há nenhuma que possa impor às outras a necessidade de observar aquelas que ela formou.

\footnotetext{
14 Pag. 16. (Nota de Le Clerc.) Cf. Locke, 2019, p. 43.

15 Pag. 22. (Nota de Le Clerc.) Cf. Locke, 2019, p. 49.
} 
Em terceiro lugar, com relação aos dirigentes das Igrejas, tais como são os bispos e os padres, é visível que seu poder, de quem quer que o tenham recebido, não vai além de fazer executar as leis da sociedade. Não chegando as leis até a coerção, nem se estendendo aos bens civis, como já se observou, segue-se daí que eles não podem usar violência alguma, nem prejudicar quem quer que seja em seus bens sem se atribuir uma autoridade que nem Deus nem os homens lhes deram. Contudo, além disso, eles estão essencialmente obrigados a exortar as pessoas à caridade e, por conseguinte, à tolerância. Apenas isso seria preciso para acalmar todas as disputas dos cristãos, pois, seguramente, toda a animosidade das pessoas provém somente da instigação daqueles que, ao invés de pregar a moderação e a paz, inflamamnas contra o próximo.

Em quarto lugar, caso se pergunte o que o magistrado deve fazer, o autor responde que ele deve deixar todo mundo na liberdade de fazer profissão das crenças que eles acreditam as mais razoáveis e impedir que seja feita violência contra qualquer pessoa por esse motivo. Ele mostra longamente as inconveniências que haveria na submissão aos caprichos dos príncipes que agem apenas pela sugestão dos eclesiásticos que mais se aproximam deles. Se fosse preciso seguir a religião do príncipe, seria preciso mudar todas as vezes em que ele muda, de modo que, se príncipes com crenças diversas se sucedessem uns aos outros, como aconteceu na Inglaterra, seria preciso que os habitantes de um país fossem em poucos anos de diversas religiões para ser salvos.

$\mathrm{V} .{ }^{16}$ Contudo, como em todas as Igrejas há duas coisas, o culto exterior e os dogmas, o autor determina os deveres do magistrado com relação a um e a outro.

Quanto às cerimônias, parece, pela definição de Igreja, que o príncipe não tem direito algum de aí estabelecer coisa alguma por sua autoridade. Não se pode dizer que, sendo coisas indiferentes, o príncipe tem direito de regulamentá-las como ele achar apropriado, porque essas coisas, sendo aplicadas no uso da Igreja, não mais têm relação com o que diz respeito à sociedade civil. Além disso, se são indiferentes em si mesmas, elas não se tornam

\footnotetext{
${ }^{16}$ Pag. 46. (Nota de Le Clerc.) Cf. Locke, 2019, p. 67.
} 
agradáveis a Deus pela aprovação do príncipe, a quem Deus não prometeu acolher o culto que os poderes estabelecessem.

Com relação aos dogmas, 1. os príncipes não devem suportar nenhum que seja contrário à sociedade civil, qualquer que seja; 2. eles não devem tolerar particularmente aqueles que, sob pretexto de religião, gostariam de privar de seus bens civis os indivíduos ou os próprios magistrados; 3. eles não devem admitir as Igrejas que, entre seus membros, não recebem senão pessoas que se submetem a uma autoridade estrangeira, à qual estão prontos para obedecer cegamente, apesar de terem seus príncipes naturais; 4 . enfim, os ateus não podem solicitar que sejam tolerados porque, não tendo religião, eles não têm consciência de nada senão daquilo que as leis civis punem.

VI. ${ }^{17}$ Diz-se que, caso sejam permitidas as assembleias separadas para servir a Deus a todos aqueles que não violam as leis do Estado, isso causará sedições e guerras civis. Contudo, o autor responde que essas assembleias não são causa de perturbações por sua natureza e que todo perigo deixaria de existir, se cada Igreja estivesse obrigada a ensinar a tolerância. Com efeito, se um povo inteiro escutasse a pregação de uma doutrina tão razoável, ele a abraçaria sem dificuldade e não haveria mais dissensões.

Caso se observe bem, descobrir-se-á que o que faz os príncipes às vezes temer certas assembleias é que eles maltratam os membros delas por causa de suas crenças ou permitem que outros os persigam. Se os poderes tivessem igual consideração e tratassem seus súditos, tanto uns quanto outros, com a mesma doçura, ninguém teria motivo de se queixar, exceto aqueles que crêem ter o direito de maltratar os que não têm suas crenças ou que fingem crer nisso para persuadir o mundo disso a fim de aumentar seu poder no Estado. Parece, assim, como o autor observa em mais de um lugar, que é apenas a dureza dos príncipes ou a liberdade que eles dão de pregar que é permitido perseguir em nome da religião e mesmo que consiste em crime não o fazer; são apenas essas razões, digo eu, que causam as perturbações e não a tolerância, que produziria em todo lugar a paz, caso dela se estivesse persuadido como se deve.

\footnotetext{
${ }^{17}$ Pag. 78. (Nota de Le Clerc.) Cf. Locke, 2019, p. 95.
} 
VII. No fina $1^{18}$ dessa Carta, o autor acreditou dever acrescentar algo acerca da natureza da heresia e do cisma. Ele diz que, dado que a heresia só tem lugar entre os que reconhecem a mesma regra de fé e de culto divino, são heréticos, geralmente falando, os que se separam da comunhão de outros que são da mesma religião que eles por causa de alguns dogmas que não estão contidos na regra comum; e, entre aqueles que reconhecem somente a Escritura Santa como regra, são especificamente heréticos aqueles que se separam dos outros por alguns dogmas que nela não estão contidos em termos formais. Disso se segue que os protestantes não podem se separar legitimamente de quem quer que seja que acolha somente a Escritura Santa e que esteja pronto para subscrevê-la; que, se alguém crê que lhe é permitido fazer passar como regra as consequências que dela extrai, é preciso que ele conceda aos outros a mesma liberdade, pois seria ridículo, por exemplo, aos luteranos querer ser os únicos intérpretes da Escritura e querer coagir os reformados a admitir suas interpretações, dado que Deus não prometeu infalibilidade nem a uns, nem a outros.

O cisma, segundo o uso ordinário dessa palavra, diz respeito apenas à disciplina ${ }^{19}$ e não é outra coisa senão uma separação que ocorre por causa de alguma parte não necessária da disciplina, que uns querem impor aos outros. Assim, somente são cismáticos aqueles que rejeitam algum artigo da disciplina que a Escritura ordena expressamente ou que querem que se observe necessariamente algum, embora a Escritura não o ordene.

Por esse método, o número de cismáticos e de heréticos é muito menor do que pensam as pessoas que nunca examinaram essa matéria; e a heresia e o cisma se encontram do lado daqueles que menos imaginam ter esse culpa.

De resto, esse livro causou tanto agrado na Inglaterra e aqui que, de pronto, foi traduzido em inglês e em holandês. ${ }^{20}$ Ele já foi impresso nessas duas línguas e talvez será visto ainda em francês. ${ }^{21}$ Com efeito, vêem-se

\footnotetext{
18 Pag. 90. (Nota de Le Clerc.) Cf. Locke, 2019, p. 105.

19 A rigor, o cisma diz respeito à disciplina (isto é, à organização da Igreja), mas também aos cultos.

${ }^{20}$ A tradução para o inglês foi feita por William Popple (1638-1708) e foi publicada em outubro de 1689. Uma segunda edição, corrigida, ocorreria em março de 1690. A tradução para o holandês, anônima, veio a lume provavelmente em agosto ou setembro de 1689 .
} 
poucos livros que tenham tratado esse tema em tão poucas palavras e com tanta clareza e força quanto este.

FIM.

\title{
3.2 Histoires des Ouvrages des Sçavans
}

\author{
Artigo II \\ Epistola de Tolerantiâ, ad Clarissimum virum T.A.R.P.T.O.L.A. scripta à \\ P.A.P.O.I.L.A., isto é, Carta sobre a Tolerância. Goudæ apud Justum ab Ho- \\ eve, 1689 . in- $12^{\circ}$ pag. $96 . .^{22}$
}

Não há talvez opinião mais deplorável nem mais incômoda para a sociedade civil do que a intolerância acerca das diversas crenças religiosas. Quando se está animado por esse espírito, é bem difícil não surgir o amargor e o distanciamento para com aqueles que não pensam as mesmas coisas que nós e não desejar sua ruína com uma impaciência pouco caridosa. Daí nascem divisões e violências que perturbam a tranquilidade da sociedade. É verdade que há quem se honre desse ódio pelo erro. A perseguição ela mesma se cobre com o belo nome de amor pela verdade e a multidão fica muito mais encantada pelos excessos de um zelo impetuoso do que pelos movimentos tranquilos de uma moderação equitativa. Contudo, frequentemente sob o pretexto de estender os limites da Igreja, cultiva-se um humor dominante e o ardor de todos os homens para fazer triunfar e para engrandecer o partido no qual se está engajado. A causa de Deus torna-se a nossa porque nossas paixões se misturam com ela. A diferença dos partidos constitui toda a religião de muitas pessoas; e aqueles que sofrem o martírio ou que se movem violentamente por dogmas que não compreendem não resistem com tanta coragem às solicitações do pecado e não velam com a mesma inquietude contra as surpresas e as tentações da carne e dos sentidos. É por isso que

\footnotetext{
${ }^{21}$ Em carta a Locke de 8/18 de julho de 1689, Limborch observou que uma tradução francesa estava em andamento (a cargo de Charles Le Cène (c. 1647-1703), refugiado huguenote na Holanda) e que ele estimativa que ela seria publicada em breve, o que acabou não acontecendo (cf. Locke, 1976-89, v. III, carta 1158). A primeira tradução da Carta sobre a Tolerância para o francês, anônima, foi publicada em Roterdã nas Euvres Diverses de Monsieur Jean Locke de 1710.

22 Texto-base da tradução: Histoires des Ouvrages des Sçavans Mois de SEPT. OCT. etc jusqu'au mois d'AOUST 1690 inclus. Tome VI. Amsterdam: chez Michel Charles Le Cène, M.D.C.C.X.X.I. p. 20-26.
} 
o Sr. Bernard ${ }^{23}$ começa sua carta com esta reflexão: que, ao menos, a caridade desses ardentes inimigos da tolerância e desses grandes fanáticos pela salvação dos outros seria menos suspeita, se eles fossem vistos igualmente armados contra o vício, que não é menos perigoso do que a heresia, e encarniçados em fazer uma guerra tão rude contra o pecado quanto contra a heresia. Contudo, o fervor de partido faz com que comumente se tenha bem menos aversão pelos viciosos do que pelos heréticos e com que se encontre uma glória mais brilhante em submeter os espíritos e lhes arrancar suas crenças do que em desenraizar o vício e plantar a virtude nos corações. As menores diferenças tornam-se monstros e aquele que muito combateu um erro o erige em heresia capital a fim de realçar a importância de suas vitórias e de seus trabalhos e de atrair sobre seu inimigo a indignação do público. Vejamos então quais princípios são aqui colocados contra essa caridade cruel e ridícula que consiste em oprimir ou degolar o próximo alegando convertê-lo e que se gaba ainda de que Deus levará em conta esse zelo injusto.

A máxima fundamental do autor é que os homens se congregaram em sociedade apenas para as comodidades temporais e para se assegurar da posse delas pelas forças reunidas da República. Assim, em virtude do poder de todos os súditos agrupado em sua pessoa, o magistrado tem o direito de castigar quem quer usurpar o bem de outrem e violar a segurança pública. Contudo, ele excede seu poder, quando busca dirigir as almas e quer prescrever e coagir a uma certa forma de religião. A razão é que as leis civis se estendem apenas sobre a conduta exterior, a qual pode ser regulamentada pelo magistrado, ao passo que a religião depende da persuasão interior e da fé, que não pode ser produzida pela autoridade. Deus não nos salva contra nós mesmos. ${ }^{24} \mathrm{O}$ príncipe pode dominar as ações e não os pensamentos; por conseguinte, ele pode fazer hipócritas e jamais verdadeiros convertidos. Aliás, seu poder não diz respeito senão à vida presente e civil e seus cuidados não devem se estender ao porvir e ao destino dos homens além do túmulo.

\footnotetext{
${ }^{23}$ Jacques Bernard (1658-1718), huguenote exilado na Holanda. Basnage de Beauval o assume como autor da Carta sobre a Tolerância possivelmente porque, em 1689, Bernard vivia como pastor em Gouda. Essa atribuição de autoria, no entanto, foi negada pelo próprio Bernard em carta publicada nas Histoires des Ouvrages des Sçavans no volume referente a dezembro de 1689 e janeiro e fevereiro de 1690 (tomo VI; cf. art. XVI, p. 278).

${ }^{24}$ Isto é, Deus não salva uma pessoa contra a vontade dela própria. Na Carta sobre a Tolerância, essa proposição se encontra expressa nos seguintes termos: "Nem Deus salvará alguém contra sua vontade" (Locke, 2019, p. 59).
} 
Quanto à Igreja, o Sr. Bernard sustenta que ela não tem poder coercitivo e que cada um nasce livre para escolher a seita que lhe parecer mais ortodoxa. A verdade requer uma aquiescência voluntária e é indigno ao ministro eclesiástico empregar a força no lugar das provas e das razões, suprir sua falta tomando emprestado o braço secular. Toda a função dos pastores se limita a instruir e exortar; e o autor tem razão em enfatizar fortemente esse ponto e de observar que o verdadeiro zelo não é nem feroz, nem bárbaro. Noutras palavras, isso é a marca certa de que o orgulho e o humor imperioso agem mais do que o amor pela verdade, que jamais se enfurece.

A objeção que os intolerantes levantam com mais confiança consiste em dizer que seria então preciso suportar os idólatras e o paganismo, e eles perguntam em seguida se, para a vergonha do Cristianismo, deseja-se reerguer os altares de falsos Deuses. Contudo, o autor não se embaraça com essa dificuldade aparentemente tão triunfante e declara sem hesitar que a religião cristã não está no direito de demolir os templos dos ídolos. Ele se faz entender por meio de um exemplo imitado do Comentário Filosófico, ${ }^{25}$ no qual se introduz de maneira muito jocosa um missionário que, perguntado pelo Rei da China e respondendo segundo seus princípios, confessa-lhe sinceramente que, em virtude dessas palavras, Obriga-os a entrar, ${ }^{26}$ ele tem a ordem por parte de Jesus Cristo de derrubar os pagodes e os templos, a partir do momento em que for mais forte, e de fazer entrar a golpes de porrete nas Igrejas Cristãs todos os chineses idólatras. ${ }^{27}$ Essa suposição da franqueza do missionário mostra suficientemente o ridículo dessa pretensão de oprimir o mais fraco. É tornar não somente a religião cristã, mas cada seita em particular, odiosa em todos os Estados em que ela não for reinante. Um dogma tão pernicioso e que sozinho deve fazer com que se feche a entrada para ela em to-

\footnotetext{
${ }^{25}$ O Comentário Filosófico, de Pierre Bayle (1647-1706), é uma obra tolerantista publicada em quatro partes: em 1686, partes 1 e $2 ; 1687$, parte $3 ; 1688$, o suplemento. O exemplo mencionado por Basnage de Beauval não se encontra na Carta sobre a Tolerância, ainda que o raciocínio por reciprocidade aí esteja presente. Trata-se, porém, de um raciocínio muito comum entre os defensores da tolerância para supor uma influência direta de Bayle sobre Locke. Além disso, convém notar que a Carta sobre a Tolerância, embora publicada em abril de 1689, havia sido redigida no inverno europeu de 1685-1686.

${ }^{26}$ Obriga-os a entrar é o mote emblemático dos intolerantes e remonta à defesa do uso da força em questões religiosas feita por Agostinho na controvérsia com os donatistas. Frequentemente utilizada em sua forma latina, compelle intrare, a expressão encontra-se na parábola do banquete (ou do banquete nupcial ou do festim, como também é chamada) em Lucas 14: 23.

${ }^{27}$ Cf. Bayle, 2014, p. 121-122, 239; Bayle, 2019, p. 24-25, 100.
} 
dos os lugares pode fazer com que se lhe aplique com justiça o apólogo da serpente que um homem aquecia em seu seio e que lhe dilacerou as entranhas. ${ }^{28}$ A mesma lei que o Cristianismo faz na Europa contra os idólatras, ele a faz contra si mesmo na Ásia e no Oriente e suas próprias máximas o entregam ao suplício e à indignação dos pagãos. A idolatria, é verdade, é um crime de lesa-majestade divina punível pela Lei de Moisés, mas os homens não receberam de Deus uma ordem para castigar tudo que ofende Sua Majestade. A avareza, por exemplo, é um vício bastante odioso e inclusive incômodo para a sociedade pela insensibilidade que inspira pela miséria alheia. Entretanto, o magistrado não ousa castigar os avaros e eles são deixados ao escárnio do mundo. Não é preciso extrair ainda mais consequências do que se passava sob a Lei. A República de Israel era uma teocracia. Deus era seu monarca visível pelos efeitos imediatos da sua presença. Assim, quem rejeitava o culto público era culpável de rebelião contra o governo em consequência dessa Lei cerimonial e política. O Sr. Bernard conclui de tudo isso que o príncipe, na qualidade de conservador da tranquilidade comum, deve dar uma plena liberdade a todas as religiões já que a consciência não é de sua competência. Desde que sejamos bons cidadãos, isso basta. Ele exclui, todavia, os ateus, que, não podendo ser vinculados nem pela sacralidade dos juramentos, nem pelo temor de uma Divindade, não podem dar garantias de sua fidelidade. Ele bane ainda aqueles que possuem o dogma da intolerância e todas as seitas cujas opiniões são contrárias à tranquilidade e ao engrandecimento da República. Não é preciso imaginar, diz ele, que essa reunião de religiões diferentes possa perturbar o Estado. As sementes da revolta não estão nos desacordos religiosos. A fonte das divisões está na animosidade que os teólogos muito se esforçam em manter e na emulação demasiado animada que reina entre as seitas. Uma quer destruir a outra. Contudo, quando o magistrado tem igual consideração e, sem ceder às lamúrias dos controversistas, reprime os ataques, não ocorre sublevação alguma causada apenas pela religião. $\mathrm{O}$ autor termina com desculpas modestas por não ter tratado seu tema mais extensamente, nem com toda elegância da língua latina..$^{29}$

\footnotetext{
${ }^{28}$ Trata-se da fábula do viajante e da serpente, fábula n. 176 ou 82, a depender da ordenação (cf. Esopo, 1995, p. 179).

${ }^{29}$ Pela leitura e comentários ao presente artigo, agradeço a Hélio Dias, Loraine Oliveira e Antônio Carlos dos Santos.
} 


\section{Referências}

[Basnage De Beauval, H.] Préface Histoires des Ouvrages des Sçavans Mois de SEPTEMBRE 1687 Rotterdam: chez chez Renier Leers, MDCLXXXVII.

Epistola de Tolerantia Histoires des Ouvrages des Sçavans SEPTEMBRE, OCTOBRE, \& NOVEMBRE 1689 Rotterdam: chez Reinier Leers, MDCLXXXIX. p. 20-26.

Epistola de Tolerantia Histoires des Ouvrages des Sçavans Mois de

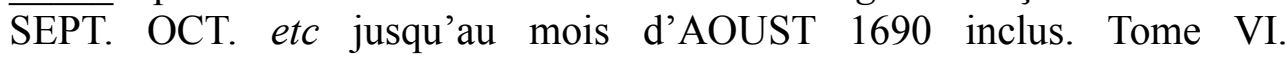
Amsterdam: chez Michel Charles Le Cène, M.D.C.C.X.X.I. p. 20-26.

BAYle, P. Commentaire Philosophique Ed. J.-M. Gros. Paris: Honoré Champion, 2014.

\section{Comentário Filosófico Tr. M. Primo Seropédica: PPGFIL-UFRRJ,}

Bots, H. L'esprit de la République des Lettres et la tolérance dans les trois premiers périodiques savants hollandais XVIIe siècle, n. 116, 1977, p. 43-57.

Bibliothèque Universelle et Historique (1686-1693) In: SGARD, J. (Dir.) Dictionnaire des Journeaux 1600-1789 Paris: Universitas, 1991. v. 12 Versão eletrônica: https://c18.net/dp/ Acesso: 09 de junho de 2020.

DiCTIONNAIRE DES JOURNALISTES: Édition électronique revue, corrigée et augmentée du Dictionnaire des journalistes (1600-1789) http://dictionnairejournalistes.gazettes18e.fr/ Acesso: 08 de junho de 2020.

DICTIONNAIRE DES JOURNEAUX: Dictionnaire des journaux (1600-1789) sous la direction de Jean Sgard https://c18.net/dp/ Acesso: 08 de junho de 2020 .

Esopo Fables Tr. D. Loayza Paris: GF Flammarion, 1995.

Huet, G. Lettre écrite de Suisse en Hollande Dordrecht: chez Theodore Goris, 1690.

JuRIEU, P. Tableau du Socinianisme La Haye: chez Abraham Troyel, 1690.

LE GAZETIER UNIVERSEL: ressources numériques sur la presse ancienne http://gazetier-universel.gazettes18e.fr/ Acesso: 08 de junho de 2020.

[Le CleRC, J.] Préface Bibliothèque Universelle et Historique de l'année M.D.C.LXXXVI, tome premier. Amsterdam: chez Wolfgang, Waesberge, Boom et Van Someren, M.D.C.LXXXVIII. 
Tolerantia, lettre latine sur cette matière. Bibliothèque Universelle et Historique de l'année M.D.C.LXXXIX, tome quinzième. Amsterdam: chez Wolfgang, Waesberge, Boom, \& van Someren, M.D.C.XC. p. 402-412.

Tolerantia, lettre latine sur cette matière. Bibliothèque Universelle et Historique de l'année M.D.C.LXXXIX, tome quinzième. Seconde édition révûe et corrigée Amsterdam: chez les héritiers d'Antoine Shelte, MDC XCIX. p. 402-412.

LE Clerc, J. Éloge Historique de feu Mr. Locke In: LoCKe, J. Euvres Diverses de M. Locke Nouvelle édition considérablement augmentée Amsterdam: chez Jean Frederic Bernard, 1732. Tome Premier.

Epistolario A cura di M. Grazia e Sina Firenze: Leo S. Olschki Editore, 1987-1997. v. 1-4.

Locke, J. Carta sobre a Tolerância Trad. F. Fortes, W. Ferreira Lima. Organização, introdução, revisão técnica, notas e comentários F. F. Loque. Belo Horizonte: Autêntica Editora, 2019.

The Correspondence of John Locke (Ed. E. S. de Beer) Oxford: Clarendon Press, 1976-89. v. I-VIII.

Marshall, J. John Locke, Toleration and Early Enlightenment Culture Cambridge: Cambridge University Press, 2006.

MiLton, J. R. Locke's Publications in the Bibliothèque Universelle et Historique British Journal for the History of Philosophy v. 19, n. 3, 2011, p. 451-472.

SimonutTI, L. Religion, Philosophy and Science: John Locke and Limborch's circle in Amsterdam In: FORCE, J. E., KATZ, D. S. (Ed.) Everything Connects Leiden: Brill, 1999. p. 293-324.

SoularD, D. Anglo-French Cultural Transmission: the case of John Locke and the Huguenots Historical Research v. 85, n. 227, 2012, p. 105-132.

The Reception of Locke's Politics: Locke in the République des Lettres In: Champion, J., Coffey, J., Harris, T., MARShall, J. (Ed.) Politics, Religion and Ideas in Seventeenth- and Eighteenth-Century Britain: essays in honour of Mark Goldie Nova York: Boydell and Brewer, 2019. p. 201-218. 